\title{
Current issues in ER and HER2 testing by IHC in breast cancer
}

\author{
Allen M Gown \\ PhenoPath Laboratories, Seattle, WA, USA
}

\begin{abstract}
The presence of estrogen receptors (ERs), as detected by immunohistochemistry (IHC), is a weak prognostic marker of clinical outcome in breast cancer, but a strong predictive marker for response, for example, to tamoxifen-based therapy. As with all IHC markers, factors such as tissue fixation (both type and duration), the choice of antibody, and the threshold for interpretation of positive immunostaining can dramatically affect test accuracy and reproducibility. For example, optimal fixation for detection of ER requires at least 6-8 $\mathrm{h}$ in formalin, and the use of newer antibodies such as SP1 may identify additional patients who might benefit from hormonal therapy. Although the threshold for positivity may be as few as $1 \%$ of tumor cells showing nuclear signal, recent studies appear to demonstrate a dichotomization of ER IHC, with the vast majority of cases showing all positive or all negative results. This may be helpful in dictating the appropriateness of hormonal therapy, but quantification of ER by IHC, or other methods, may play a more important role in the future. Breast cancers with human epidermal receptor protein-2 (c-erbB-2; HER2) alterations are critical to identify because such tumors require unique treatment, including the use of targeted therapies such as trastuzumab. HER2 alterations at the DNA (amplification) and protein (overexpression) level usually occur in concert, and both fluorescence in situ hybridization (FISH) or IHC can be accurate methods to assess these alterations. However, recent studies have suggested that serious reproducibility issues exist in both FISH and IHC HER2 studies. To address this, a joint committee of both the American Society for Clinical Oncologists and the College of American Pathologists has promulgated new guidelines for HER2 testing. These include the following: (a) recommendations for tissue fixation for more than 6 and less than $48 \mathrm{~h}$; (b) new scoring criteria, including a new threshold of $30 \%$ strong immunostaining for classification of $3+$; (c) introduction of the term 'equivocal' to characterize HER2 studies that are $2+$ by IHC and/or show HER2/chromosome 17 ratios of between 1.8 and 2.2 by FISH; (d) requirements for laboratories to validate HER2 assays, generally through the cross-testing of cases with another HER2 methodology, with laboratories required to attain $95 \%$ concordance for both positive and negative tests; (e) participation in HER2 proficiency testing.
\end{abstract}

Modern Pathology (2008) 21, S8-S15; doi:10.1038/modpathol.2008.34

Keywords: breast cancer; estrogen receptor; HER2; immunohistochemistry

\section{Prognostic and predictive markers}

Antibody-defined markers in breast cancer can be employed in two different ways: as prognostic markers (those that can independently forecast clinical outcome) and as predictive markers (those that can independently predict response to a particular therapy).

\section{Part 1: Estrogen Receptors}

Estrogen and progesterone receptors are weak prognostic markers of outcome ${ }^{1}$ and strong predictive markers of response to endocrine, for example,

Correspondence: Dr AM Gown, MD, PhenoPath Laboratories, 551 North 34th Street, Suite 100, Seattle, WA 98103, USA.

E-mail: gown@phenopath.com

Received 28 January 2008accepted 28 January 2008 tamoxifen-based, therapy, ${ }^{2}$ and are the only immunohistochemistry (IHC)-based breast markers to have received the imprimatur of a consensus committee of the College of American Pathologists. ${ }^{3}$ Estrogen receptors (ERs) expression has long been considered to be present in two-thirds of breast cancers, ${ }^{2}$ but more recent studies suggest that its incidence may be closer to $70 \% .{ }^{4}$ ER status is strongly influenced by tumor grade and histology; ${ }^{5}$ as demonstrated by Nadji et $a l^{4}$ in a study of almost 6000 tumors, virtually all grade I tumors are ER positive, as are pure tubular, colloid, and classic lobular carcinoma.

Analysis of progesterone receptor (PR) expression is generally reported along with ER expression, and IHC determination of PR expression has now been clinically validated. ${ }^{6}$ It has further been conclusively demonstrated that PR status is independently associated with disease-free and overall survival, that is, patients with ER-positive/PR-positive 
tumors have a better prognosis than patients with ER-positive/PR-negative tumors, who in turn have a better prognosis than patients with ER-negative/ PR-negative tumors. ${ }^{7}$

As with all IHC studies of therapeutic targets, accurate and perhaps quantitative assessment of the results are critical. There are several major factors that can dramatically affect the apparent ER and PR status of a breast cancer as determined by IHC, including tissue fixation, choice of anti-ER or anti-PR antibody, and determination of thresholds for reporting positive results. As documented by Rhodes et al, ${ }^{8}$ there is wide variation in the reporting of results of estrogen and PR status, and all of these factors contribute to this.

\section{Choice of specimen and fixation}

The first question to be addressed is the type of specimen on which hormone receptor studies are most optimally performed, for example, needle core biopsies or resection specimens. Whereas the published literature suggests a concordance rate of $60-100 \%$ in breast samples of individual patients when core needle vs resection specimens are examined, more recent studies employing the most up-to-date methodologies in the context of larger number of cases show near 100\% concordance between needle core and resection specimens. ${ }^{9}$ However, Mann and colleagues have demonstrated that as many as $9 \%$ of women may have falsenegative ER IHC studies if their resection, rather than needle core biopsy, is utilized. These falsenegative studies may be a consequence of inadequate fixation. Indeed, Goldstein et $a l^{10}$ have demonstrated that at least $6-8 \mathrm{~h}$ of formalin fixation time for breast biopsies is required to obtain reliable ER determination by IHC; pathologists therefore risk false-negative ER studies when tissues are underfixed, as can happen in a specimen that comes in at the end of the day and is put immediately into a tissue processor. Given the lack of control some laboratories have over the fixation duration, and given the lability of the ER antigen, it is still advisable to look for 'built-in' positive controls in the form of non-neoplastic breast epithelium when identifying an ER-negative case.

\section{Choice of antibody}

Although a number of anti-ER antibodies are available, the ideal antibody is one that is both robust and has been clinically validated; to date, there are only three such antibodies, $1 \mathrm{D} 5,{ }^{11} 6 \mathrm{~F} 11,{ }^{12}$ and SP $1^{13}$ clones, which have all been demonstrated to produce results that correlate with clinical outcome; all have also been demonstrated to be equal or superior to ligand-binding assays in this respect. ${ }^{11-14}$ Published data further suggest that the SP1 rabbit monoclonal may be the most robust of these reagents and better in identifying those patients most likely to respond to tamoxifen than the 1D5 clone. ${ }^{13}$ Whereas earlier studies had suggested that the $\mathrm{ER}-/ \mathrm{PR}+$ group of tumors corresponds to about $10 \%$ of all cases, ${ }^{15}$ more recent studies using more robust antibodies suggest that this latter group probably represents one composed of false-negative ER studies; with optimal immunohistochemical methods, the number of tumors in this subset is near zero, or zero. ${ }^{4}$

\section{Threshold for positivity}

The use of clinically validated, reproducible, and standardized cutoffs for determining the scoring of positive results is critical. While a wide range of arbitrary cutoffs (eg 5 or $10 \%$ of tumor cells) are employed by different laboratories, in fact only one cutoff for both ER and PR immunostaining has been clinically validated as predicting response to tamoxifen-based therapy. In the landmark study of Harvey et $a,^{12}$ a nine-point, semiquantitative 'Allred' score (ranging from 0-8) was performed on a series of almost 2000 patients and results were correlated with response to adjuvant endocrine therapy. Although there was a strong direct association between the level of ER expression, that is, the Allred score, and response to hormonal therapy, statistical analysis revealed that, by calibrating the definition of ER positivity to those with Allred scores greater than 2, the largest number of patients could be identified who benefited from adjuvant endocrine therapy. An Allred score of 3 or more (ie the definition of ER positivity) corresponds to as few as $1 \%$ of cells showing weak immunostaining signal. More recent studies have demonstrated the identical cutoff (ie 1\% of cells with weak signal) for IHC analysis of PR. ${ }^{6}$ Ideally, however, the laboratory should employ an ER antibody using a cutoff score for positivity that has been clinically validated.

The value of further quantification of ER and PR at this time is uncertain. It has been shown that it is feasible to quantify ER and/or PR signals using different proprietary instruments ${ }^{16-18}$ or even relatively simple microcomputer-based image analysis techniques. ${ }^{19,20}$ Recent published studies showing a dichotomized, bimodal distribution of ER expression using the 1D5 monoclonal antibody have called into question the necessity of quantification, suggesting that ER is almost always either completely positive or completely negative. ${ }^{4,21}$ Inasmuch as not all ER-positive patients respond to endocrine therapy, and because ER appears, for example, by ligand-binding assays to be a continuous rather than binary parameter in breast, it is not yet clear that one should discard the notion of quantification of ER and PR analysis by IHC. $^{22}$ Dichotomization can result in loss of information (Figure 1). In the future, other techniques might prove more efficacious than IHC in quantifying ER, ${ }^{23}$ but if the question is one of whether a patient should be treated with endocrine therapy, a dichotomized result from IHC studies may be the most appropriate. ${ }^{24}$ 
S10
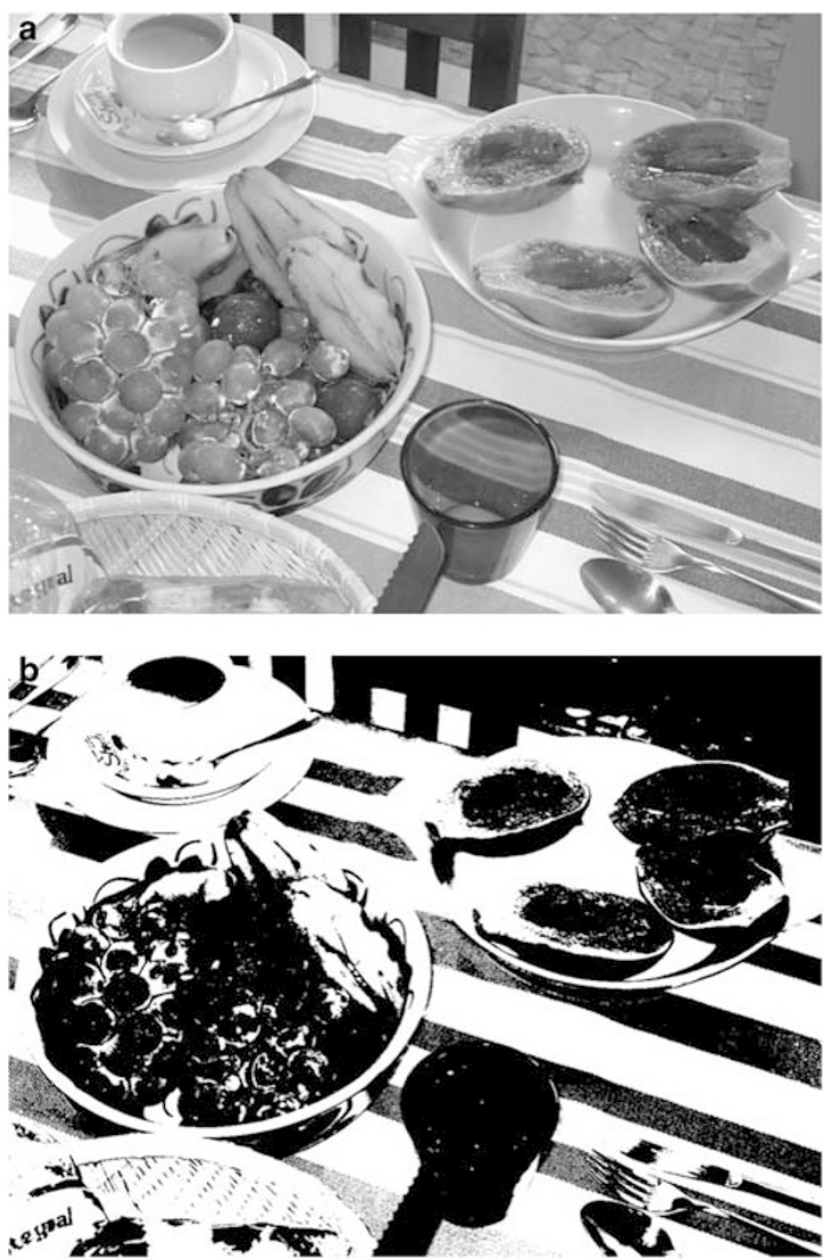

Figure 1 Dichotomizing a continuous variable can result in loss of information. The grayscale image (a, top) has been 'dichotomized' by increasing the gamma so that only black and white remain (b, bottom). Has the same loss of information happened with ERs, in which a continuous variable has been dichotomized with IHC to be all positive or all negative?

The role of hormone receptor studies in ductal carcinoma in situ (DCIS) was demonstrated. NSABP Protocol B-24 showed that patients with hormone receptor-positive DCIS will likely have a significant risk reduction of subsequent invasive disease when given anti-estrogen therapy, compared with hormone receptor-negative tumors. ${ }^{25}$

\section{Part 2: Human Epidermal Receptor Protein-2}

The human epidermal receptor protein-2 (c-erbB-2; HER2) oncogene protein is a transmembrane glycoprotein in the epidermal growth factor receptor family. It is expressed at low levels in a variety of normal epithelia, including breast duct epithelium, but amplification of the HER2 gene and concomitant protein overexpression are present in $10-20 \%$ of primary breast cancers (Figure 2). Determination of HER2 status in breast cancer is important, as it has been determined that it is a prognostic as well as a predictive marker. HER2 overexpression and/or gene amplification is an independent prognostic marker of clinical outcome, in both node-negative and node-positive patients. ${ }^{26-29}$ The major utility of HER2, however, is as a predictive marker. As a predictive marker, HER2 status has been shown to predict sensitivity to anthracycline-based chemotherapy regimens. ${ }^{30-33}$ In addition, amplification of the HER2 gene and/or overexpression of the HER2 protein confers relative resistance to cytoxan-based regimens $^{34}$ and tamoxifen-based therapies in the setting of ER-positive breast cancers. ${ }^{35}$ Perhaps most importantly, breast cancers with HER2 alterations are targets for treatment with trastuzumab, a humanized monoclonal antibody, which has been shown to markedly improve response rate and survival when added to chemotherapy or used as a monotherapy. ${ }^{36-38}$ Recent studies have demonstrated that adjuvant trastuzumab can reduce the risk of recurrence by one half, and mortality by one third, in early-stage breast cancer patients. ${ }^{39,40}$ Other agents, targeting the HER2 gene product, have also demonstrated clinical utility, ${ }^{41}$ and several more are in development. Trastuzumab is one of the first successful therapies that has been custom-designed to identify a tumor-associated molecule.

HER2 testing has become an essential part of the clinical evaluation of all breast cancer patients in the United States, and accurate HER2 results are critical in identifying patients for whom this targeted therapy is appropriate. This is particularly important, given the cardiotoxic side effects of trastuzumab seen in approximately $1.4 \%$ of patients receiving the drug as a single agent, ${ }^{36,42,43}$ and even in higher percentages of patients receiving trastuzumab concomitantly with paclitaxel $(13 \%)$ or anthracyclines $(27 \%),{ }^{37}$ as well as the high cost of the drug. ${ }^{44,45}$

HER2 IHC poses even greater challenges than does ER IHC, as both accurate as well as semi-quantitative assessment of the results of HER2 immunostaining are critical. Many of the same factors critical to accurate ER immunostaining apply to HER2 immunostaining, such as tissue fixation, choice of antibody, and determination of thresholds for reporting positive results.

Although a tight association between HER2 gene amplification and protein overexpression has been documented in breast cancers by Western and Northern blot analyses, ${ }^{26}$ Press et $a l^{46}$ have demonstrated that IHC on deparaffinized, formalin-fixed tissue can be quite variable in its ability to identify HER2-amplified tumors. The high level of discordance between HER2 protein expression by IHC and HER2 gene amplification by fluorescence in situ hybridization (FISH) has been documented in several studies. Discordance rates may be as high as $20 \%$ when HER2 testing is performed in lowvolume, local laboratories, whereas discordance is believed to be lower in high-volume, central 

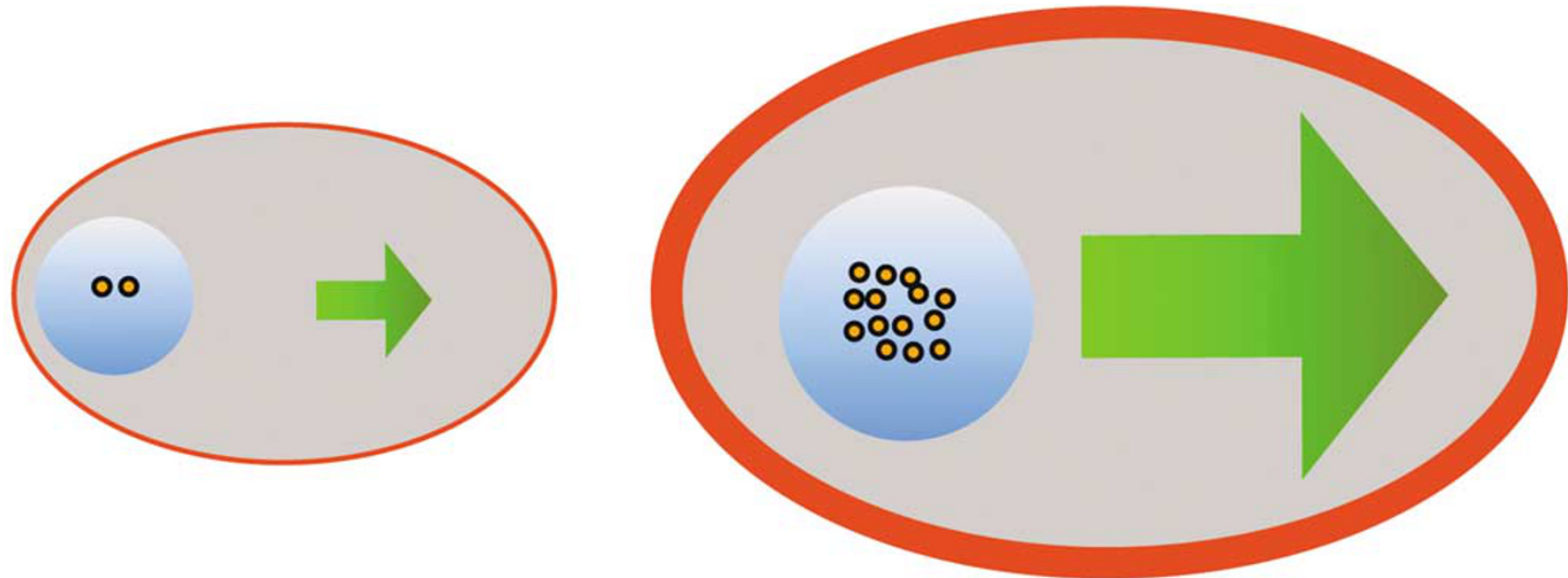

Figure 2 Cartoon showing relationship of HER2 DNA (orange dots), mRNA (green arrows), and protein levels (red peripheral band) in normal breast epithelium (left) compared with HER2-positive breast cancer (right). Note that the vast majority of HER2-positive tumors show parallel marked increases of DNA, mRNA, and protein, but HER2 protein is present at low levels in normal breast epithelium.

laboratories. ${ }^{47,48}$ More recent studies continue to document significant levels of discordance between results of HER2 studies performed at local and central laboratories, for example, $18 \%$ for IHC and $12 \%$ for $\mathrm{FISH}^{49}$ and a $21.8 \%$ false-positive rate and $8.9 \%$ false-negative rate for HER2 IHC (vs by FISH) at local laboratories. ${ }^{50}$

Addressing this issue of HER2 test accuracy, the American Society of Clinical Oncologists (ASCO) and the College of American Pathologists (CAP) have recently released new guidelines for laboratory testing of HER2 status in breast cancer. ${ }^{51,52}$ HER2 IHC scoring is reported as negative $(0 / 1+)$, equivocal $(2+)$, or positive $(3+)$ (Figure 3 ). Among other things, these guidelines require validation of HER2 testing by all laboratories performing HER2 testing, which entails documenting 95\% concordance rates between cases that are IHC $3+$ and FISH-amplified, and between cases that are IHC $0 / 1+$ and non-FISHamplified. HER2 FISH is reported as amplified (HER/ CEP17 ratio $>2.2$ ), equivocal (ratio 1.8-2.2), or negative (ratio $<1.8$ ).

A number of factors appear to improve concordance levels between HER2 assessment by IHC and FISH. Image analysis has been demonstrated to improve interobserver variability among pathologists evaluating HER2 IHC, and also to produce better concordance with HER2 FISH. ${ }^{53,54}$ My laboratory has previously demonstrated the value of an ongoing quality assurance program, entailing parallel testing by IHC on all FISH cases, which significantly improves concordance between the two methods. ${ }^{55}$

A significant decrease in false-positive (IHC3 +1 FISH-) results can also be obtained through a modification of the Food and Drug Administration (FDA)-approved scoring system for HER2 IHC by obtaining a normalized IHC score for the breast cancer. ${ }^{56}$ This score is obtained by subtracting the score representing the level of immunostaining on the non-neoplastic breast epithelium from the score representing the level of immunostaining on the tumor. Our initial studies demonstrated this to be the case in tissues fixed in alcoholic formalin, but more recent studies have demonstrated that this 'normalization' technique can yield very high concordance between IHC and FISH results; indeed, concordance rates approaching that recommended by the ASCO-CAP panel cannot be obtained without using such a technique. ${ }^{57}$

The accuracy of diagnostic assays for HER2 in breast cancer is extremely important, as HER2 status is not only a prognostic marker but also predictive of response to chemotherapy, particularly to HER2targeted therapy such as trastuzumab. ${ }^{36-38}$ The diagnostic tests most widely used are IHC and FISH, measuring protein overexpression and gene amplification, respectively. There is a wide reported variation in both the accuracy of, and concordance between, these two methods. In general, documented concordance rates have fallen well below the 95\% threshold mandated by the new ASCO-CAP guidelines, with many studies demonstrating concordance rates (excluding $2+$ cases) closer to $80-90 \% .^{58-63}$ The wide range of reported concordance rates between IHC and FISH assessment of HER2 status in breast cancer reflects, at least in part, the wide variation in methodology, instrumentation, and experience of the laboratories performing the testing.

The sensitivity and accuracy of HER2 testing by IHC is highly dependent upon both preanalytical factors, such as tissue fixation, ${ }^{64}$ and analytic factors, such as choice of anti-HER2 antibody employed in the IHC assay. ${ }^{46}$ Although the introduction of HercepTest ${ }^{\mathrm{TM}}$, an FDA-approved kit for IHC testing, was intended to introduce a high level of accuracy and reproducibility to HER2 IHC testing, in fact HercepTest has been demonstrated in several studies to produce significant numbers of false 
S12
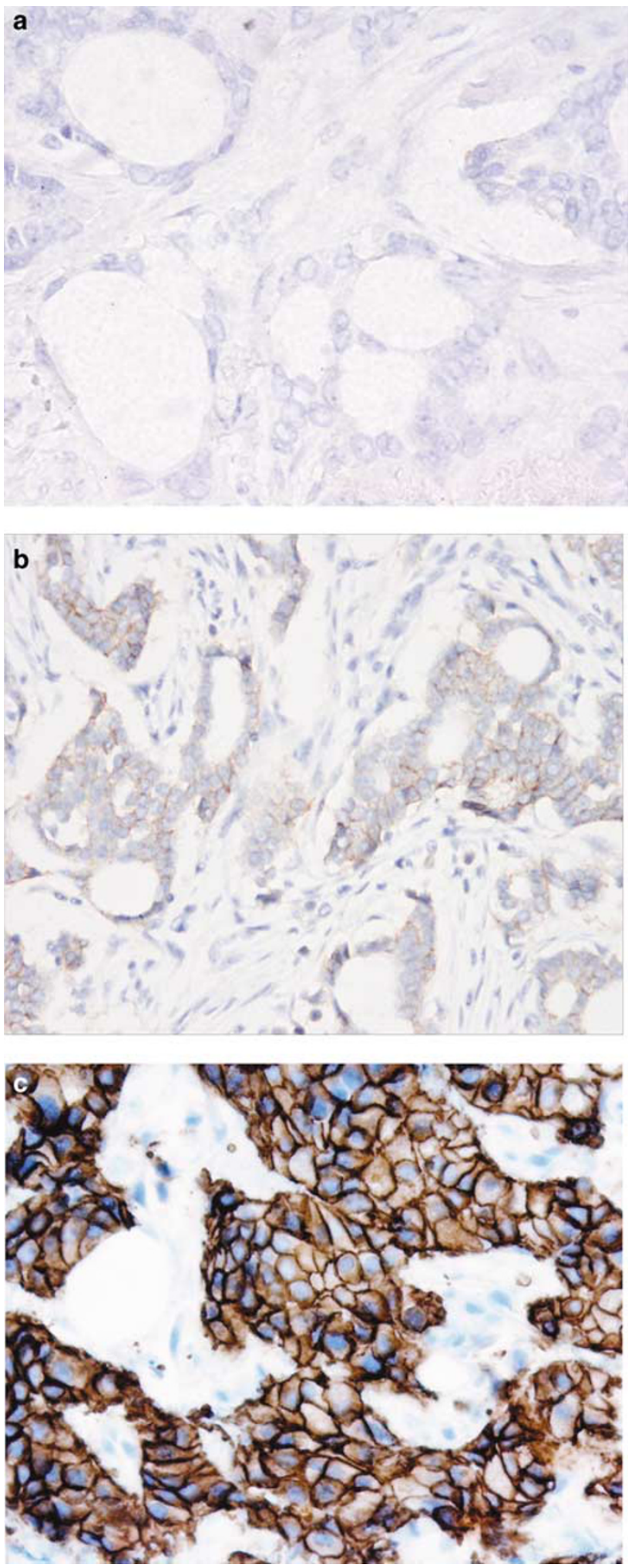

Figure 3 Examples of HER2 immunostaining: (a) 0 (negative); (b) $2+$ (equivocal); (c) $3+$ (positive). According to the ASCO-CAP guidelines, if the laboratory's assays have been properly validated, and assuming proper fixation, no further testing would be required for (a) or (c). The equivocal test (b) would require further testing by another modality, for example, FISH (original magnification $\times 200$ ). positives (ie cases demonstrated to be non-amplified by FISH). ${ }^{56,61,65,66}$ Furthermore, the accuracy of HercepTest in identifying HER2 status in deparaffinized sections of a series of 117 well-characterized breast cancers was $88.9 \%{ }^{67}$

Although attaining near-perfect correlation between assessment of HER2 status by IHC and FISH is a laudable goal, discordance between these two measurements may be a function both of biology as well as laboratory error. For example, Pauletti et al ${ }^{68}$ have demonstrated that at least $3 \%$ of breast cancers show protein overexpression in the absence of concomitant gene amplification, implying that such cancers manifest high levels of protein expression through a mechanism other than gene amplification. Several investigators have shown that polysomy of chromosome 17 can account for a small subset of breast cancers showing 3 + levels of HER2 immunostaining but no amplification by FISH when the HER2/chromosome 17 ratio is evaluated. ${ }^{69-71}$

The new ASCO-CAP guidelines mandate significant changes in HER2 testing in laboratories throughout the United States. As technical handling of tissue continues to be a significant factor in standardization of test quality, the new guidelines mandate fixation in $10 \%$ neutral-buffered formalin for a minimum of $6 \mathrm{~h}$ and a maximum of $48 \mathrm{~h}$ duration. Extremely high concordance between IHC and FISH assessment of HER2 status in breast cancer is achievable, but to attain this high level of concordance, many laboratories may need to revise their tissue fixation and IHC methodology and scoring methods to achieve the high level of concordance mandated by the ASCOCAP guidelines.

\section{Choice of antibody}

Although there are a wide range of antibodies available to the HER2 protein, the ability of these antibodies to detect overexpression is extremely variable. ${ }^{46}$ As of the time of writing this article, the United States FDA had approved two different antibodies for IHC assessment of HER-2 expression, the HercepTest, which is based on the Dako A0485 polyclonal antibody, and the CB11 monoclonal antibody, available only in kit form for use on the Ventana autostainer; these two antibodies are also available outside of their kit formats, but without the imprimatur of FDA approval.

\section{Scoring positive cases}

Although the FDA-approved scoring system of 0 , $1+, 2+$, and $3+$ (see table) was tailored for the HercepTest kit, and despite the fact that applies only to the determination of eligibility for trastuzumab therapy, it has become the de facto scoring system for most antibodies and test formats. However, use of the FDA-approved scoring system does not automatically ensure accurate assessment of HER2 status, as was demonstrated in our study ${ }^{56}$ documenting the improved accuracy of HER2 IHC studies by using a subtraction scoring system in which the 
signal score of the non-neoplastic breast epithelium is subtracted from that of the tumor. Non-neoplastic breast epithelium expresses low levels of the HER2 gene product that may produce a $1+$ or even $2+$ signal, depending upon tissue fixation and processing parameters, and if this is ignored a significant number of false-positive breast cancer HER2 scores will result. ${ }^{56}$

\section{FDA Scoring System for HER2}

\begin{tabular}{|c|c|}
\hline Score & Definition \\
\hline 0 & No immunostaining \\
\hline $1+$ & Weak immunostaining, less than $30 \%$ of tumor cells \\
\hline $2+$ & $\begin{array}{l}\text { Complete membranous staining, either uniform or weak } \\
\text { in at least } 10 \% \text { of cells }\end{array}$ \\
\hline $3+$ & $\begin{array}{l}\text { Uniform intense membranous staining in at least } 30 \% \\
\text { of cells }\end{array}$ \\
\hline
\end{tabular}

\section{IHC validation}

One important new requirement of the ASCO-CAP guidelines is that of validation of IHC by all laboratories. To be validated, an IHC assay must have only $5 \%$ or less of samples classified as either positive or negative disagree with a 'validated' assay. If a laboratory cannot meet this standard, it should not be performing HER2 IHC and should send specimens to another laboratory with a validated assay. Cases scored as equivocal (ie $2+$ by IHC) are not expected to be concordant but should be tested by another method (eg FISH).

\section{Exclusion criteria}

The ASCO-CAP guidelines mandate certain preanalytical factors that can result in rejection of the specimen for IHC evaluation of HER2 status. These include tissues fixed in fixatives other than neutralbuffered formalin, needle core biopsies fixed in formalin for less than $1 \mathrm{~h}$, excisional biopsies fixed in formalin for less than $6 \mathrm{~h}$, and any specimen fixed in formalin longer than $48 \mathrm{~h}$. However, these are not 'absolute' exclusion criteria, and it is possible to accept such specimens if the assay can be validated under those conditions. In contrast, an exclusion criteria that is 'fatal' is the presence of severe artifact (eg crush or edge effect).

\section{References}

1 Hahnel R, Woodings T, Vivian AB. Prognostic value of estrogen receptors in primary breast cancer. Cancer 1979;44:671-675.

2 Allred DC, Harvey JM, Berardo M, et al. Prognostic and predictive factors in breast cancer by immunohistochemical analysis. Mod Pathol 1998;11:155-168.

3 Fitzgibbons PL, Page DL, Weaver D, et al. Prognostic factors in breast cancer. College of American Patholo- gists Consensus Statement 1999. Arch Pathol Lab Med 2000;124:966-978.

4 Nadji M, Gomez-Fernandez C, Ganjei-Azar P, et al. Immunohistochemistry of estrogen and progesterone receptors reconsidered: experience with 5,993 breast cancers. Am J Clin Pathol 2005;123:21-27.

5 Anderson WF, Chatterjee N, Ershler WB, et al. Estrogen receptor breast cancer phenotypes in the surveillance, epidemiology, and end results database. Breast Cancer Res Treat 2002;76:27-36.

6 Mohsin SK, Weiss H, Havighurst T, et al. Progesterone receptor by immunohistochemistry and clinical outcome in breast cancer: a validation study. Mod Pathol 2004;17:1545-1554.

7 Bardou VJ, Arpino G, Elledge RM, et al. Progesterone receptor status significantly improves outcome prediction over estrogen receptor status alone for adjuvant endocrine therapy in two large breast cancer databases. J Clin Oncol 2003;21:1973-1979.

8 Rhodes A, Jasani B, Balaton AJ, et al. Frequency of oestrogen and progesterone receptor positivity by immunohistochemical analysis in 7016 breast carcinomas: correlation with patient age, assay sensitivity, threshold value, and mammographic screening. J Clin Pathol 2000;53:688-696.

9 Hodi Z, Chakrabarti J, Lee AH, et al. The reliability of assessment of oestrogen receptor expression on needle core biopsy specimens of invasive carcinomas of the breast. J Clin Pathol 2007;60:299-302.

10 Goldstein NS, Ferkowicz M, Odish E, et al. Minimum formalin fixation time for consistent estrogen receptor immunohistochemical staining of invasive breast carcinoma. Am J Clin Pathol 2003;120:86-92.

11 Barnes DM, Harris WH, Smith P, et al. Immunohistochemical determination of oestrogen receptor: comparison of different methods of assessment of staining and correlation with clinical outcome of breast cancer patients. Br J Cancer 1996;74:1445-1451.

12 Harvey JM, Clark GM, Osborne CK, et al. Estrogen receptor status by immunohistochemistry is superior to the ligand-binding assay for predicting response to adjuvant endocrine therapy in breast cancer. J Clin Oncol 1999;17:1474-1481.

13 Cheang MC, Treaba DO, Speers CH, et al. Immunohistochemical detection using the new rabbit monoclonal antibody SP1 of estrogen receptor in breast cancer is superior to mouse monoclonal antibody 1D5 in predicting survival. J Clin Oncol 2006;24: 5637-5644.

14 Pertschuk LP, Feldman JG, Kim YD, et al. Estrogen receptor immunocytochemistry in paraffin embedded tissues with ER1D5 predicts breast cancer endocrine response more accurately than H222Sp gamma in frozen sections or cytosol-based ligand-binding assays. Cancer 1996;77:2514-2519.

15 Osborne CK, Yochmowitz MG, Knight III WA, et al. The value of estrogen and progesterone receptors in the treatment of breast cancer. Cancer 1980;46: 2884-2888.

16 Bacus S, Flowers JL, Press MF, et al. The evaluation of estrogen receptor in primary breast carcinoma by computer-assisted image analysis. Am J Clin Pathol 1988;90:233-239.

17 Esteban JM, Ahn C, Battifora $\mathrm{H}$, et al. Predictive value of estrogen receptors evaluated by quantitative immunohistochemical analysis in breast cancer. Am J Clin Pathol 1994;102:S9-S12. 
18 Esteban JM, Ahn C, Mehta P, et al. Biologic significance of quantitative estrogen receptor immunohistochemical assay by image analysis in breast cancer. Am J Clin Pathol 1994;102:158-162.

19 Mofidi R, Walsh R, Ridgway PF, et al. Objective measurement of breast cancer oestrogen receptor status through digital image analysis. Eur J Surg Oncol 2003; 29:20-24.

20 Lehr HA, Mankoff DA, Corwin D, et al. Application of photoshop-based image analysis to quantification of hormone receptor expression in breast cancer. J Histochem Cytochem 1997;45:1559-1565.

21 Collins LC, Botero ML, Schnitt SJ. Bimodal frequency distribution of estrogen receptor immunohistochemical staining results in breast cancer: an analysis of 825 cases. Am J Clin Pathol 2005;123:16-20.

22 Allred DC, Mohsin SK. ER expression is not bimodal in breast cancer [letter]. Am J Clin Pathol 2005;124: 474-475.

23 Gong Y, Yan K, Lin F, et al. Determination of oestrogenreceptor status and ERBB2 status of breast carcinoma: a gene-expression profiling study. Lancet Oncol 2007;8: 203-211.

24 Schnitt SJ. Estrogen receptor testing of breast cancer in current clinical practice: what's the question? J Clin Oncol 2006;24:1797-1799.

25 Allred CD, Bryant J, Land S, et al. Estrogen receptor expression as a predictive marker of the effectiveness of tamoxifen in the treatment of DCIS: findings from NSABP protocol B-24. Breast Cancer Res Treat 2002;76:S36

26 Slamon DJ, Godolphin W, Jones LA, et al. Studies of the HER-2/neu proto-oncogene in human breast and ovarian cancer. Science 1989;244:707-712.

27 Tandon AK, Clark GM, Chamness GC, et al. HER-2/neu oncogene protein and prognosis in breast cancer. J Clin Oncol 1989;7:1120-1128.

28 Paik S, Hazan R, Fisher ER, et al. Pathologic findings from the National Surgical Adjuvant Breast and Bowel Project: prognostic significance of erbB-2 protein overexpression in primary breast cancer [Prior annotation incorrect]. J Clin Oncol 1990;8: 103-112.

29 Press MF, Bernstein L, Thomas PA, et al. HER-2/neu gene amplification characterized by fluorescence in situ hybridization: poor prognosis in node-negative breast carcinomas. J Clin Oncol 1997;15:2894-2904.

30 Villman K, Sjostrom J, Heikkila R, et al. TOP2A and HER2 gene amplification as predictors of response to anthracycline treatment in breast cancer. Acta Oncol 2006;45:590-596.

31 Pritchard KI, Shepherd LE, O'Malley FP, et al. HER2 and responsiveness of breast cancer to adjuvant chemotherapy. N Engl J Med 2006;354:2103-2111.

32 Cardoso F, Durbecq V, Larsimont D, et al. Correlation between complete response to anthracycline-based chemotherapy and topoisomerase II-alpha gene amplification and protein overexpression in locally advanced/metastatic breast cancer. Int J Oncol 2004;24: 201-209.

33 Thor AD, Berry DA, Budman DR, et al. erbB-2, p53, and efficacy of adjuvant therapy in lymph nodepositive breast cancer [see comments]. J Natl Cancer Inst 1998;90:1346-1360.

34 Menard S, Valagussa P, Pilotti S, et al. Response to cyclophosphamide, methotrexate, and fluorouracil in lymph node-positive breast cancer according to HER2 overexpression and other tumor biologic variables. J Clin Oncol 2001;19:329-335.

35 De Laurentiis M, Arpino G, Massarelli E, et al. A metaanalysis on the interaction between HER-2 expression and response to endocrine treatment in advanced breast cancer. Clin Cancer Res 2005;11:4741-4748.

36 Vogel CL, Cobleigh MA, Tripathy D, et al. Efficacy and safety of trastuzumab as a single agent in first-line treatment of HER2-overexpressing metastatic breast cancer. J Clin Oncol 2002;20:719-726.

37 Slamon D, Pegram M. Rationale for trastuzumab (Herceptin) in adjuvant breast cancer trials. Semin Oncol 2001;28:13-19.

38 Cobleigh MA, Vogel CL, Tripathy D, et al. Multinational study of the efficacy and safety of humanized anti-HER2 monoclonal antibody in women who have HER2-overexpressing metastatic breast cancer that has progressed after chemotherapy for metastatic disease. J Clin Oncol 1999;17:2639-2648.

39 Piccart-Gebhart MJ, Procter M, Leyland-Jones B, et al. Trastuzumab after adjuvant chemotherapy in HER2positive breast cancer. N Engl J Med 2005;353: 1659-1672.

40 Romond EH, Perez EA, Bryant J, et al. Trastuzumab plus adjuvant chemotherapy for operable HER2positive breast cancer. N Engl J Med 2005;353: 1673-1684.

41 Geyer CE, Forster J, Lindquist D, et al. Lapatinib plus capecitabine for HER2-positive advanced breast cancer. N Engl J Med 2006;355:2733-2743.

42 Baselga J, Carbonell X, Castaneda-Soto NJ, et al. Phase II study of efficacy, safety, and pharmacokinetics of trastuzumab monotherapy administered on a 3-weekly schedule. J Clin Oncol 2005;23:2162-2171.

43 Leyland-Jones B, Gelmon K, Ayoub JP, et al. Pharmacokinetics, safety, and efficacy of trastuzumab administered every three weeks in combination with paclitaxel. J Clin Oncol 2003;21:3965-3971.

44 Cox MC, Figg WD, Thurman PW. No rational theory for drug pricing. J Clin Oncol 2004;22:962-963.

45 Elkin EB, Weinstein MC, Winer EP, et al. HER-2 testing and trastuzumab therapy for metastatic breast cancer: a cost-effectiveness analysis. J Clin Oncol 2004;22: 854-863.

46 Press MF, Hung G, Godolphin W, et al. Sensitivity of HER-2/neu antibodies in archival tissue samples: potential source of error in immunohistochemical studies of oncogene expression. Cancer Res 1994;54: 2771-2777.

47 Roche PC, Suman VJ, Jenkins RB, et al. Concordance between local and central laboratory HER2 testing in the breast intergroup trial N9831. J Natl Cancer Inst 2002;94:855-857.

48 Paik S, Bryant J, Tan-Chiu E, et al. Real-world performance of HER2 testing-National Surgical Adjuvant Breast and Bowel Project experience. J Natl Cancer Inst 2002;94:852-854.

49 Perez EA, Suman VJ, Davidson NE, et al. HER2 testing by local, central, and reference laboratories in specimens from the North Central Cancer Treatment Group N9831 intergroup adjuvant trial. J Clin Oncol 2006;24: 3032-3038.

50 Press MF, Sauter G, Bernstein L, et al. Diagnostic evaluation of HER-2 as a molecular target: an assessment of accuracy and reproducibility of laboratory testing in large, prospective, randomized clinical trials. Clin Cancer Res 2005;11:6598-6607. 
51 Wolff AC, Hammond ME, Schwartz JN, et al. American Society of Clinical Oncology/College of American Pathologists Guideline recommendations for human epidermal growth factor receptor 2 testing in breast cancer. Arch Pathol Lab Med 2007;131:18.

52 Wolff AC, Hammond ME, Schwartz JN, et al. American Society of Clinical Oncology/College of American Pathologists guideline recommendations for human epidermal growth factor receptor 2 testing in breast cancer. J Clin Oncol 2007;25:118-145.

53 Tawfik OW, Kimler BF, Davis M, et al. Comparison of immunohistochemistry by automated cellular imaging system (ACIS) versus fluorescence in-situ hybridization in the evaluation of HER-2/neu expression in primary breast carcinoma. Histopathology 2006;48: 258-267.

54 Bloom K, Harrington D. Enhanced accuracy and reliability of HER-2/neu immunohistochemical scoring using digital microscopy. Am J Clin Pathol 2004;121: 620-630.

55 Yaziji H, Goldstein LC, Barry TS, et al. HER-2 testing in breast cancer using parallel tissue-based methods. JAMA 2004;291:1972-1977.

56 Jacobs TW, Gown AM, Yaziji H, et al. Specificity of HercepTest in determining HER-2/neu status of breast cancers using the United States Food and Drug Administration-approved scoring system. J Clin Oncol 1999;17:1983.

57 Gown AM, Goldstein LC, Barry TS, et al. High concordance between immunohistochemistry and fluorescence in situ hybridization testing for HER2 status in breast cancer requires a normalized IHC scoring system. Mod Pathol 2008 (in press).

58 Jacobs TW, Gown AM, Yaziji H, et al. Comparison of fluorescence in situ hybridization and immunohistochemistry for the evaluation of HER-2/neu in breast cancer. J Clin Oncol 1999;17:1974-1982.

59 Couturier J, Vincent-Salomon A, Nicolas A, et al. Strong correlation between results of fluorescent in situ hybridization and immunohistochemistry for the assessment of the ERBB2 (HER-2/neu) gene status in breast carcinoma. Mod Pathol 2000;13:1238-1243.

60 Kakar S, Puangsuvan N, Stevens JM, et al. HER-2/neu assessment in breast cancer by immunohistochemistry and fluorescence in situ hybridization: comparison of results and correlation with survival. Mol Diagn 2000;5:199-207.
61 Pauletti G, Dandekar S, Rong H, et al. Assessment of methods for tissue-based detection of the HER-2/neu alteration in human breast cancer: a direct comparison of fluorescence in situ hybridization and immunohistochemistry. J Clin Oncol 2000;18:3651-3664.

62 Dybdal N, Leiberman G, Anderson S, et al. Determination of HER2 gene amplification by fluorescence in situ hybridization and concordance with the clinical trials immunohistochemical assay in women with metastatic breast cancer evaluated for treatment with trastuzumab. Breast Cancer Res Treat 2005;93:3-11.

63 Reddy JC, Reimann JD, Anderson SM, et al. Concordance between central and local laboratory HER2 testing from a community-based clinical study. Clin Breast Cancer 2006;7:153-157.

64 Penault-Llorca F, Adelaide J, Houvenaeghel G, et al. Optimization of immunohistochemical detection of ERBB2 in human breast cancer: impact of fixation. J Pathol 1994;173:65-75.

65 Roche PC, Ingle JN. Increased HER-2 with US Food and Drug Administration-approved antibody [letter]. J Clin Oncol 1999;17:434.

66 Lebeau A, Deimling D, Kaltz C, et al. HER-2/neu analysis in archival tissue samples of human breast cancer: Comparison of immunohistochemistry and fluorescence in situ hybridization. J Clin Oncol 2001; 19:354-363.

67 Press MF, Slamon DJ, Flom KJ, et al. Evaluation of HER-2/neu gene amplification and overexpression: comparison of frequently used assay methods in a molecularly characterized cohort of breast cancer specimens. J Clin Oncol 2002;20:3095-3105.

68 Pauletti G, Godolphin W, Press MF, et al. Detection and quantitation of HER-2/neu gene amplification in human breast cancer archival material using fluorescence in situ hybridization. Oncogene 1996;13:63-72.

69 Ma Y, Lespagnard L, Durbecq V, et al. Polysomy 17 in HER-2/neu status elaboration in breast cancer: effect on daily practice. Clin Cancer Res 2005;11:4393-4399.

70 Varshney D, Zhou YY, Geller SA, et al. Determination of HER-2 status and chromosome 17 polysomy in breast carcinomas comparing HercepTest and PathVysion FISH assay. Am J Clin Pathol 2004;121:70-77.

71 Lal P, Salazar PA, Ladanyi M, et al. Impact of polysomy 17 on HER-2/neu immunohistochemistry in breast carcinomas without HER-2/neu gene amplification. J Mol Diagn 2003;5:155-159. 